\title{
高分子材料合成创新实验课程思政教学探索与实践
}

问毅 ${ }^{*}$, 颜静, 姚东东

西北工业大学化学与化工学院, 西安 710129

摘要: 在高分子材料合成创新实验课程中紧密结合课程内容, 深入挖掘课程思政素材, 围绕高分子材料中的 “卡脖 子技术” “中国故事” “工程伦理” “工匠精神” 等四方面, 培养学生的 “学术自信” “科技报国” “科学发展观” 和 “科学精神”。

关键词：课程思政；高分子材料合成创新实验；中国故事；科学发展观

中图分类号: G64; O6

\section{Exploration and Practice of Course Ideology and Politics in Polymer Materials Synthesis Innovation Laboratory}

Yi Yan *, Jing Yan, Dongdong Yao

School of Chemistry and Chemical Engineering, Northwestern Polytechnical University, Xi'an 710129, China.

\begin{abstract}
During the course of polymer materials synthesis innovation laboratory, corresponding cases of course ideology and politics were deeply explored by close combination with the course content. Generally, the "academic self-confidence", "science and technology serving the country", "scientific outlook on development", and "scientific spirit" were cultivated through the four aspects of "strangle hold technology", "story of china", "engineering ethics", and "craftsman spirit".
\end{abstract}

Key Words: Course ideology and politics; Polymer materials synthesis innovation laboratory; Story of China; Scientific outlook on development

2016年12月7日, 习近平总书记在全国高校思想政治工作会议上强调: 要用好课堂教学这个主渠 道, 提升思想政治教育亲和力和针对性, 满足学生成长发展需求和期待, 使各类课程与思想政治理 论课同向同行，形成协同效应 ${ }^{[1]}$ 。为了把思想政治教育贯穿人才培养体系，全面推进高校课程思政 建设, 发挥好每门课程的育人作用及提高高校人才培养质量, 教育部于 2020 年 5 月 28 日印发实施《高 等学校课程思政建设指导纲要》(以下简称《纲要》) ${ }^{[2]}$ 。化学是一门实验性学科, 在课程的讲授过程 中更应该注重学生核心素养的全方面培育，落实立德树人，实现价值引领和知识传授的同频共振。 《纲要》明确指出: 专业实验实践课程, 要注重学思结合、知行统一, 增强学生勇于探索的创新精 神和善于解决问题的实践能力。对于工学类专业课程, 要注重强化学生工程伦理教育, 培养学生精

收稿: 2020-08-08; 录用: 2020-09-23; 网络发表: 2020-10-15

“通讯作者, Email: yanyi@nwpu.edu.cn

基金资助: 2019 校高水平课程建设—— “课程思政” 示范课程; 2019 研究生高水平课程建设(课程思政); 西北工业大学 2020 年 “课程思政” 示 范课程建设项目; 第二批陕西省新工科研究与实践项目 (20GZ110109); 2020 年高分子材料与工程专业综合实验设计; 2020 年校高等教育研究基 金(G2020KY0701); 2018 年度校级教育教学改革项目(W015304); 2019 年研究生教育教学改革项目(19GA210101); 2019 学位与研究生教育研究 基金(19GZ220101)；2019 年本科教学项目(19GH0101127，19GH01001031，19GZ1201) 
益求精的大国工匠精神，激发学生科技报国的家国情怀和使命担当。

高分子是一门年轻的学科, 其课程具有很强的理论性和实用性, 在课程的讲授过程中既要结合 相关理论讲授高分子材料的设计、合成和加工等知识, 更重要的是要结合国家亟需, 以 “卡脖子” 技术、“中国故事” 甚至身边事物中的高分子相关原理与应用等向学生传输 “学术自信” “科技报国” “科学发展观” 和 “工程伦理与专业认同” 等。

本文将结合笔者及教学团队在高分子材料合成创新实验教学中深入挖掘思政素材(表1), 开展课 程思政教学的一些探索与尝试。

表1 “高分子材料合成创新实验” 课程思政元素举例 ${ }^{[3]}$

\begin{tabular}{|c|c|c|}
\hline 实验内容 & 相关事例 & 思政元素融合点 \\
\hline 单体和引发剂的精制 & $\begin{array}{l}\text { 抗击新冠肺炎疫情中重要材料4-甲基-1- } \\
\text { 戊烯单体的卡脖子难题 }\end{array}$ & $\begin{array}{l}\text { 通过分析卡脖子技术, 树立学生的民族危 } \\
\text { 机感和使命感, 培养其学术自信的信心和 } \\
\text { 科技报国的决心 }\end{array}$ \\
\hline 甲基丙烯酸甲酯的本体聚合 & 隐形眼镜材料的发展历史 & 高分子材料发展对于人类健康的重要意义 \\
\hline 可逆加成-断裂链转移(RAFT)试剂的合成 & 汤华藥博士在RAFT聚合方面的事迹 & 华人科学家对于世界高分子学科发展的突 \\
\hline 苯乙烯的RAFT聚合 & & 出贡献和精益求精的 “工匠精神” \\
\hline 苯乙烯的原子转移自由基聚合(ATRP) & 王锦山博士在ATRP聚合方面的事迹 & \\
\hline 聚丙烯酸水凝胶的制备及其基本性能测试 & $\begin{array}{l}\text { 西北工业大学潘光教授团队在水下无人 } \\
\text { 潜航器研制方面的成果 }\end{array}$ & $\begin{array}{l}\text { 服务国防, 献身国防的高尚情操与使命担 } \\
\text { 当 }\end{array}$ \\
\hline 聚乙烯醇缩甲酫的制备 & $\begin{array}{l}\text { 中科院宁波材料研究所朱锦研究员在无 } \\
\text { 醛木材粘合剂方面的成果 }\end{array}$ & 绿色发展观念和科学发展观 \\
\hline 双酚A环氧树脂的制备 & $\begin{array}{l}\text { 西北工业大学孙曼灵教授在环氧树脂方 } \\
\text { 面的研究成果及其献身国防的事迹 }\end{array}$ & $\begin{array}{l}\text { “西迁精神” 以及服务国防、献身国防的 } \\
\text { 高尚情操和家国情怀 }\end{array}$ \\
\hline 聚苯胺的合成 & $\begin{array}{l}\text { 麦克德尔米德教授在导电高分子方面的 } \\
\text { 重要贡献 }\end{array}$ & 科学家的敏锐眼光和科研协作的精神 \\
\hline $\begin{array}{l}\text { 界面聚合法制备尼龙及其力学性能测试 } \\
\text { 羧甲基纤维素的合成 }\end{array}$ & $\begin{array}{l}\text { 卡罗瑟斯的科研经历和重要贡献 } \\
\text { 张俐娜院士在纤维素方面的重要贡献 }\end{array}$ & $\begin{array}{l}\text { 科学家的探索精神和不屈不挠的奋斗精神 } \\
\text { 中国高分子科学家的卓越贡献和绿色发展 } \\
\text { 的观念 }\end{array}$ \\
\hline $\begin{array}{l}\text { 无㿝乳液聚合制备亚微米级胶体颗粒 } \\
\text { 悬浮聚合制备多孔聚合物微球 }\end{array}$ & $\begin{array}{l}\text { 西北工业大学张秋禹教授团队在国防亟 } \\
\text { 需高分子树脂方面的代表性成果 }\end{array}$ & 面向国家重大需求的使命担当 \\
\hline 聚氨酯泡沫材料的合成 & $\begin{array}{l}\text { 中国深海载人潜水器中浮力材料的卡脖 } \\
\text { 子问题 }\end{array}$ & $\begin{array}{l}\text { 科学家为国铸重器, 努力拼搏, 打破国外 } \\
\text { 技术垄断的使命担当 }\end{array}$ \\
\hline 同步辐射散射在高分子有序结构表征中的应用 & $\begin{array}{l}\text { 中国同步辐射光源建设过程及成就 } \\
\text { 程正迪院士在高分子有序结构方面的代 } \\
\text { 表性成果 }\end{array}$ & $\begin{array}{l}\text { 中国科学家艰苦奋斗, 勇于创新铸造国之 } \\
\text { 重器的感人事迹和精益求精的大国工匠精 } \\
\text { 神以及华人科学家的家国情怀 }\end{array}$ \\
\hline
\end{tabular}

\section{1 高分子材料中的 “卡脖子” 技术与 “学术自信”}

十八大以来，习近平总书记曾在多个场合反复强调: “核心技术受制于人是我们最大的隐患”, “核心技术是国之重器。要下定决心、保持恒心、找准重心，加速推动信息领域核心技术突破”。

高分子材料广泛应用于国防军工、航空航天等国民经济的重要领域, 我国在很多关键高分子材 料领域中仍然存在很多亟待解决的 “卡脖子” 难题。团队在课程的讲授过程中, 紧密结合课程相关 实验内容, 挖掘与高分子材料相关的 “卡脖子” 技术难题。一方面, 从基础理论的角度告诉学生 “万 丈高楼平地起”, 要解决 “卡脖子” 技术必需具有坚实的理论基础; 另一方面, 结合我国科学家在攻 
克 “卡脖子” 技术难题中的感人事迹, 向学生传输 “专业认同” 与 “学术自信”。其中最典型的一个 事例就是深海勇士号载人潜水器研制过程中，研究团队实现固体浮力材料国产化的事迹。

本课程的一个重要实验就是聚氨酯泡沫材料的合成。在合成出泡沫材料的同时, 为了让学生进 一步理解泡沫材料的重要性, 拓展其应用领域, 我们引入了深海载人潜水器中的关键材料——浮力 材料。早在2002年科技部就将深海载人潜水器研制列为国家高技术研究发展计划重大专项, 并启动 了 “蛟龙号” 载人深潜器的自行设计与研制工作。从 2009 年至 2012 年, 蛟龙号接连取得 1000 米级、 3000 米级、5000米级和 7000 米级海试成功, 并于 2012年在马里亚纳海沟创造了下潜7062米的中国载 人深潜纪录和世界同类作业型潜水器最大下潜记录。然而, 其中的关键材料之一, 即固体浮力材料 始终依赖国外进口。在课程的实验中, 学生已经初步了解了聚氨酯发泡材料的主要成分及制备过程, 但是对这类材料在国防军工中的应用了解甚少。为此, 教学团队引入了发泡材料的制备及其重要应 用的事例, 即深海潜水器中的 “卡脖子” 问题之一固体浮力材料。中国科学院理化技术研究所理化 技术所张敬杰研究员团队勇于接受研制任务, 于2016年开始研制国产化的固体浮力材料。在团队多 年研究的基础上, 经过半年的艰苦努力, 终于实现了高性能固体浮力材料的全面国产化, 并最终应 用于 “万泉号” 和 “深海勇士号” 载人潜水器, 大大提升了我国在海洋, 尤其是深海探测方面的国 际地位 ${ }^{[4]}$ 。

这个事例不仅仅加深了学生对于聚合物发泡材料应用的理解, 增强了对高分子材料与工程专业 的 “职业认同” , 更重要的是科学家为国铸重器, 努力拼搏, 打破国外技术垄断的使命担当极大地 增强了大家的 “学术自信” 和 “科技报国” 的决心和使命感。

\section{2 高分子材料中的 “中国故事”与 “科技报国”}

课程思政的一个重要举措就是讲好 “中国故事”, 深入挖掘身边的思政元素, 以身边人、身边事 来潜移默化地影响学生。对于高分子材料合成创新实验课程而言, 我们主要是结合著名科学家的事 迹和西北工业大学在高分子材料服务国防重要需求等方面的事例展开。

本课程的一个重要实验是苯乙烯的可逆加成-断裂链转移(RAFT)聚合。在以往的高分子化学实 验课程教学中, 学生了解到的高分子合成方法都是国外科学家发明的, 为了增强学生的 “科技自 信”, 我们引入了华裔汤华楸博士发明、发展RAFT聚合的例子。众所周知, RAFT聚合是一种先进 的可控自由基聚合技术, 是由澳大利亚联邦科学与工业研究院的Graeme Moad、Ezio Rizzardo和汤华 楸三名科学家提出的。汤华炎博士是越南华裔, 其求学经历以及RAFT技术的发现过程充满着无数艰 辛, 通过讲解其发明、发展RAFT聚合的事例, 让学生体会到科学背后不屈的毅力和勤奋的追求。同 时, 汤博士在发明RAFT技术并当选澳大利亚科学院院士之后, 依然能够回国在北京化工大学创建 “北京化工大学可控活性自由基聚合前沿研究中心”，无不体现了其 “科技报国” 的拳拳爱国之心， 这也鼓舞着学生奋发图强、科技报国的决心 ${ }^{[5]}$ 。

高分子材料在国民经济主战场和国防重要领域有着重要应用, 为了让学生了解高分子材料研制 背后的科学家故事和科技研发历程, 教学团队还深入挖掘相关的课程思政元素(表1)。比如, 高分子 材料合成创新实验中我们指导学生了解并合成出了聚丙烯酸水凝胶材料。一方面, 水凝胶作为一种 交联网络结构, 常见于生活中的凉粉等食品; 另一方面, 在国防军工等重要领域也需要水凝胶材料。 为了让学生体会这种 “貌似普通” 的材料的重要应用, 结合我校国防军工特色, 我们引入了我校航 海学院潘光教授团队领衔设计的我国首款滑扑一体自主变形仿生柔体潜航器的案例。为了实现仿生 “魔鬼鱼” 的扑动、滑翔、急停、转弯等动作, 潘教授研究团队与我校化学与化工学院合作开发了 一系列高强度、高变形的水凝胶材料, 并应用于 “魔鬼鱼” 的主体结构 ${ }^{[6]}$ 。在深刻体会科技工作者服 务国防、献身国防的高尚情操与使命担当的同时, 教学团队更是结合 “魔鬼鱼” 研制过程中对水凝 胶材料力学性能、吸水率和可变形性等参数的要求, 指导学生从水凝胶单体、网络结构设计、交联 程度等方面展开思考, 很好地实现了 “课程思政”与 “知识传授” 的同频共振。 


\section{3 高分子材料中的 “工程伦理” 与 “科学发展观”}

如《纲要》所指出：工程类专业课程思政的一个重要方面就是从哲学的角度剖析 “工程伦理”， 让学生切身体会化学这把 “双刃剑”, 形成责任关怀, 深入理解化学工业与社会发展之间的相互制 约关系, 树立和落实 “科学发展观”。为此, 结合课程内容, 我们挖掘了以下三个事例 ${ }^{[7]}$ 。

第一个事例是聚甲基丙烯酸甲酯与隐形眼镜。本课程的第一个合成实验就是聚甲基丙烯酸甲酯 的合成。为了拓展聚甲基丙烯酸甲酯的应用, 我们向学生介绍了隐形眼镜的发展历程。众所周知, 第一代隐形眼镜材料就是聚甲基丙烯酸甲酯, 其便捷性给近视患者带来了巨大的便利。然而由于聚 甲基丙烯酸甲酯透气性、透水性很差, 容易导致眼球干涩甚至失明。Otto Wichterle等人深入挖掘聚 甲基丙烯酸甲酯类材料的问题根源, 成功开发出聚甲基丙烯酸羟乙酯软性接触镜, 为近视患者带来 了福音。这个事例很好地说明了化学工作者应有的 “责任关怀” , 也很好地阐述了高分子材料进步 对人类健康的重大影响。

第二个事例是聚乙烯醇缩甲醛与无醛粘合剂。本课程的一个重要实验就是聚乙烯醇缩甲醛(107 胶水)的制备及其粘结性能测试。聚乙烯醇缩甲醛胶水被广泛地应用于粘贴壁纸和塑料地板等建筑装 修领域。但是, 其原料之一就是致癌性较强的甲醛, 严重影响着人类的日常生活。在课程讲授过程 中, 我们引导学生立足绿色环保的科学发展观, 从 “人文关怀” 的角度出发, 思考如何制备无醛粘 结剂。为了加深学生对无醛粘结剂设计的理解, 教学团队引入了我国科学家中国科学院宁波材料技 术与工程研究所朱锦博士在无醛粘结剂方面的事迹。朱锦博士在研制生物基无醛木材胶粘剂的过程 中, 合理地处理了 “人一环境-发展” 三者之间的关系, 所体现的绿色发展观念和科学发展观深刻地 从专业角度影响了学生的职业定位和科技伦理观念。

第三个事例是白色污染与可降解高分子材料。在目前的高分子材料合成创新实验中, 所合成的 高分子材料基本都是难降解高分子材料, 如果使用不当很容易造成白色污染。在课程教学过程中, 我们引导学生从合成方法学、单体设计、催化剂设计、聚合工艺等角度展开设计环境友好型、可降解 型高分子材料的思考。为了进一步说明可降解高分子材料的设计理念, 教学团队引入了我国科学家 张俐娜院士和陈学思院士在该领域的突出贡献。比如陈学思院士团队立足吉林省的玉米产业, 开展 了可降解聚乳酸和聚-已内酯研究, 既有效服务了国民经济, 又为解决白色污染提供了一条可行的路 线, 体现了 “科学进步”与 “社会发展”之间的和谐与统一。

以上三个事例既阐述了相关的化学原理, 又蕴含着 “对立统一” “否定之否定” 的哲学规律; 同时还涵盖了与化学和高分子学科相关的 “工程伦理” ，有助于树立和落实 “科学发展观”。

\section{4 高分子材料中的 “工匠精神” 与 “科学精神”}

实验类课程思政的一个重要方面就是培养学生实事求是、科学严谨的 “工匠精神” 和 “科学精 神”。为此, 在课程讲授过程中, 我们引入了以下两个重要案例。

一个案例是甲基丙烯酸甲酯本体聚合中的阻聚剂。为了培养学生实事求是的科学精神, 我们在 实验中 “故意设置了障碍”。在常规的甲基丙烯酸本体聚合实验中, 为了增加趣味性, 一般建议学 生向聚合体系中加入 “小物件”, 从而制备 “人工琥珀” 。在本课程教学中, 我们建议学生向聚合 体系中加入准备好的无机颜料。众所周知, 甲基丙烯酸甲酯的本体聚合是自由基过程, 需要严格避 免阻聚剂的存在。而在我们准备的无机颜料中, 黄颜色的 $\mathrm{FeCl}_{3}$ 是典型的氧化还原型阻聚剂, 选用其 作为添加剂将无法得到目标产物。面对 “貌似失败” 的实验, 我们引导学生分析问题的根源, 培养 其实事求是的科学态度 ${ }^{[8]}$ 。

第二个事例是原子转移自由基聚合(ATRP)与王锦山博士。原子转移自由基聚合是一类先进的可 控自由基聚合技术, 广泛地应用于科学研究和高性能聚合物制备中。为了提升课程的前沿性, 我们 引入了苯乙烯的ATRP聚合实验。在实验过程中, 结合部分同学制备的聚苯乙烯分子量分布较宽等问 题, 我们重点从实验操作和实验技能等方面展开分析。一方面, 告诉大家高超的玻璃工操作、严谨 
而巧妙的实验设计、缜密的逻辑思维在王锦山博士发现ATRP过程中的重要作用; 另一方面, 通过实 验演示向大家介绍ATRP实验操作要点。这个事例既让学生了解了ATRP的原理与操作, 又培养了其 缜密严谨的科学态度和 “精益求精” 的工匠精神 ${ }^{[9]}$ 。

\section{5 课程思政效果}

学生的学习效果和成果产出是衡量课程思政建设效果的重要指标。在高分子材料合成创新实验 教学过程中, 通过 “人为引入实验变量” “实验环节拓展” “翻转课堂” 等形式鼓励学生对实验现 象进行客观分析, 对实验内容进行合理拓展, 对实验相关原理进行深入理解, 培养其严谨认真的科 学态度和缜密的逻辑思维。这些尝试取得了如下成效: (1) 学生的科研兴趣和热情得到有效提升。无 论是在每年的大学生创新训练项目、节能减排竞赛还是实验技能竞赛中, 本课程的学生都积极参与, 近三年参与度超过 $80 \%$; (2) 学生的创新意识得到提高。比如在本课程中的 “实验拓展” 环节中, 吴 亚东同学巧妙设计了聚乙烯醇缩甲醛胶水的粘结性能测试实验, 相关结果发表于 《化学教育》 ${ }^{[8]}$; 张 玉同学设计的创意水凝胶图片入选《化学教育》封面; (3) 学生的家国情怀和利用专业知识服务社会 的能力得到提升。比如疫情期间, 李宇琛、钟丰璘等同学依托专业知识写作并发表题为《 “新冠肺 炎” 抗疫中使用的重要高分子材料》科普论文 ${ }^{[10]}$, 起到了很好的科普效果。

\section{6 结语}

落实立德树人，实现价值引领和知识传授的同频共振是课程思政的主要任务。在课程讲授过程 中要紧紧围绕课程内容, 深入挖掘课程思政案例, 通过讲好 “中国故事”, 发现身边人和事中蕴含的 课程思政元素, 做到 “润物无声” 地影响学生和塑造学生, 让其感受到 “有温度、有感情” 的课堂。 同时, 作为理科教师一定要加强自身的政治修养和文学素养, 善于捕捉课程知识中蕴含的思政内容。 实践出真知, 在实践类课程中融入课程思政元素, 对学生进行潜移默化的思政教育, 更容易实现立 德树人的根本任务。

\section{参 考 文 献}

[1] 新华社. 习近平: 把思想政治工作贯穿教育教学全过程. (2016-12-08) [2019.11.28].

http://www.xinhuanet.com//politics/2016-12/08/c_1120082577.htm

[2] 高等学校课程思政建设指导纲要. [2020-06-18]. http://www.moe.gov.cn/srcsite/A08/s7056/202006/t20200603_462437.html

[3] 问毅, 姚东东, 颜静. 高分子材料合成创新实验. 西安: 西北工业大学出版社, 2019.

[4] 王平, 王平, 严开祺, 潘顺龙, 张敬杰. 工程研究-跨学科视野中的工程, 2016, No. 2, 223.

[5] 李岸龙, 梁晖, 卢江. 高分子通报, 2007, No. 9, 15 .

[6] 高妍, 郑声宇. 科技创新与品牌, 2017, No. 11, 58.

[7] 间毅, 颜静, 姚东东, 顾军渭. 大学化学, 2020,35(5), 249.

[8] 颜静, 姚东东, 耿旺昌, 史学涛, 顾军渭, 吴亚东, 间毅. 化学教育, 2019, 40 (24), 34.

[9] 颜静, 耿旺昌, 姚东东, 问毅. 化学教育, 2020,41 (14), 32.

[10] 颜静, 李宇琛, 钟丰璘, 闻毅. 大学化学, 2020,35 (12), 71. 